\title{
INHIBITION OF L-THYROXINE MONODEIODINATION BY THYROXINE ANALOGS*
}

\author{
By FRANK C. LARSON AND EDWIN C. ALBRIGHT \\ (From the Department of Medicine, University of Wisconsin Medical School, Madison, Wis.)
}

(Submitted for publication January 24, 1961 ; accepted March 3, 1961)

The concept that structural analogs of thyroxine might antagonize the peripheral action of this hormone was first advanced by Woolley (1). Subsequently, a large number of analogs has been examined for thyroxine antagonism. Assay methods have involved amphibian metamorphosis, goiter prevention, and oxygen consumption techniques. The results of these studies were reviewed by Selenkow and Asper (2).

It has been proposed that thyroxine has no physiological activity except as a precursor of the peripherally active form of the thyroid hormone (3). The initial step in this "activation" may be the enzymatic monodeiodination of thyroxine to 3,5,3'-triiodo-L-thyronine. The evidence for this concept was summarized recently (4). This reaction has been observed in vitro in rat kidney slices, where it was found that the enzymatic activity varied with the state of thyroid activity, being decreased in hypothyroid and increased in hyperthyroid animals (5). This in vitro system, therefore, permits a direct approach to the study of thyroxine antagonists. The following experiments were undertaken to test the possibility that structural analogs will compete for the deiodination of thyroxine, and to determine the structural requirements for this inhibitory activity.

\section{METHODS}

White male rats of the Sprague-Dawley strain, weighing 180 to $250 \mathrm{~g}$, were used throughout. Hyperthyroidsm was induced by feeding a Rockland rat ration containing 2 per cent desiccated thyroid for a period of 2 weeks. The desiccated thyroid was withheld for 24 to 48 hours prior to sacrifice.

The kidneys were removed under ether anesthesia,

* This work was supported in part by the Research Committee of the Graduate School from funds supplied by the Wisconsin Alumni Research Foundation, and by a grant from Smith, Kline and French Laboratories. Presented in part November 5, 1960, at the Annual Meeting of the Central Society for Clinical Research, Chicago, Ill. cooled to $4^{\circ} \mathrm{C}$ by immersion in chilled Ringer's solution, sliced with a Stadie-Riggs apparatus, weighed, and incubated at $37^{\circ} \mathrm{C}$ in Krebs-Ringer phosphate solution in the presence of the appropriate amount of $\mathrm{I}^{121}$-labeled thyroxine and analog. A flask to which no analog was added served as a control for each experiment. The analogs used are listed in Table I. All were dissolved in 50 per cent propylene glycol in water. The purity of the labeled thyroxine was checked each day by chromatography. Siliconized Warburg vessels were used in the incubation to prevent loss of the iodine and iodinated thyronine compounds through adsorption on the surface of the glass.

At the end of incubation the slices were removed, rinsed and homogenized in $2 \mathrm{ml}$ of distilled water. The homogenate was extracted with 30 vol of $n$-butyl alcohol. The extract was concentrated in vacuo to $2 \mathrm{ml}$ and a $100 \mu 1$ aliquot chromatographed in descent using a tertamyl alcohol-2 $\mathrm{N} \mathrm{NH}_{4} \mathrm{OH}$ solvent system (6). A $100 \mu 1$ aliquot of the incubation media was also chromatographed in descent using a 20 per cent propionic acid in tert-amyl alcohol solvent system as the developer. This system widely separates iodide from the thyronine compounds. In each system, colorimetrically identifiable quantities of known reaction products were added as marker compounds just prior to chromatography. The position of the thyronine compounds was determined with a 4-aminoantipyrine reagent as seen in Figure 1. Iodide was 1ocated on the chromatograph strip by the use of a starchiodate reagent; radioactivity was located with a chromatogram scanner. The amount of labeled compound was determined by planimetry of the area under the curve.

In the calculation of the quantity of triiodothyronine derived from the labeled substrate it was assumed that thyroxine was randomly labeled at the $3^{\prime}$ and $5^{\prime}$ positions. It follows that only one-half of the triiodothyronine derived from thyroxine would be labeled. The quantity of labeled thyroxine originally present would be the sum of the thyroxine activity remaining and twice the activity present as triiodothyronine. The percentage of triiodothyronine derived from thyroxine originally present was therefore calculated as follows:

$$
\% T_{3}=\frac{2 T_{3}}{2 T_{3}+T_{4}} \times 100
$$

where $T_{3}=$ measured radioactivity as triiodothyronine at the conclusion of the incubation and $T_{4}=$ measured radioactivity remaining as thyroxine at the conclusion of the period of incubation. 
TABLE I

Inhibition of L-thyroxine monodeiodination by thyroxine analogs *

\begin{tabular}{lccr}
\hline \hline \multicolumn{1}{c}{ Analogs } & \multicolumn{2}{c}{$\begin{array}{c}\text { Per cent inhibition with } \\
\text { increasing molar con- } \\
\text { centrations }\end{array}$} \\
\hline $3,5,3^{\prime}, 5^{\prime}$-Tetraiodothyropropionic & & & \\
acid & 28 & 76 & 86 \\
$3,3^{\prime}, 5^{\prime}$-Triiodo-DL-thyronine & 29 & 71 & 81 \\
D-thyroxine & 15 & 45 & 57 \\
O-methyl-DL-thyroxine & 14 & 30 & 54 \\
3,5,3'-Triiodo-L-thyronine & 3 & 39 & 42 \\
$3,5-$ Diiodo-DL-tyrosine & 0 & 4 & 10 \\
$\alpha-$ Methyl thyroxamine & 0 & 0 & 8 \\
\hline
\end{tabular}

* The analogs were kindly furnished by the following investigators: $3,5,3^{\prime}, 5^{\prime}$-tetraiodothyropropionic acid and 3,5,3'-triiodo-L-thyronine by Dr. Arthur Heming (Smith, Kline and French); 3,3',5'-triiodo-DL-thyronine by Dr. Robert Kroc (Warner-Chilcott); D-thyroxine by Dr. Leonard Ginger (Travenol); O-methyl-DL-thyroxine by Dr. H. A. Lardy (Institute for Enzyme Research, Univ. of Wisconsin); $\alpha$-methyl thyroxamine by Dr. W. Brady and Dr. H. A. Lardy (unpublished observations; Institute for Enzyme Research, Univ. of Wisconsin). Purity of the analogs was checked by chromatography.

The per cent inhibition by the analog was calculated as follows:

$$
\text { inhibition in } \%=100-[(A / B) \times 100]
$$

where $A=$ per cent yield of triiodothyronine in the presence of inhibitor, and $B=$ per cent yield of triiodothyronine in the absence of inhibitor.

\section{RESULTS}

Establishment of conditions optimal for inhibitor studies. In previous experiments with the thyroxine monodeiodinating system, a $10^{-7} \mathrm{M}$ thyroxine concentration was used. Since the ratio of substrate to enzyme concentration is of primary importance in inhibitor experiments, preliminary studies were undertaken to determine whether this concentration was suitable. In the first experiments, the labeled thyroxine was held constant at $10^{-\tau} \mathrm{M}$ concentration and the weight of the tissue varied. The change in yield of triiodothyronine with respect to the weight of the tissue is plotted in Figure 2. No appreciable increase occurred beyond $100 \mathrm{mg}$ of tissue. Using $100 \mathrm{mg}$ of tissue, the substrate was varied from $10^{-10}$ to $10^{-4} \mathrm{M}$ concentration by the progressive addition of nonradioactive thyroxine to a constant amount of radioactive thyroxine. As seen in Figure 3, at substrate concentrations less than $10^{-\tau} \mathrm{M}$, no appreciable increase in yield occurred, due presumably to the nonspecific binding of thyroxine to proteins which rendered it inaccessible to the deiodinating enzyme. At molar concentrations higher than $10^{-7}$, the yield of triiodothyronine fell sharply as the capacity of the enzyme was exceeded. In subsequent experiments, $10^{-\tau} \mathrm{M}$ concentration of substrate and 100 $\mathrm{mg}$ of tissue were used. The yield of triiodothyronine during a 6 hour period is plotted in Figure 4. A 4 hour incubation period was used in the inhibitor experiments largely for convenience.

Inhibitor study. Results of a representative experiment are shown in Figure 5. In this ex-

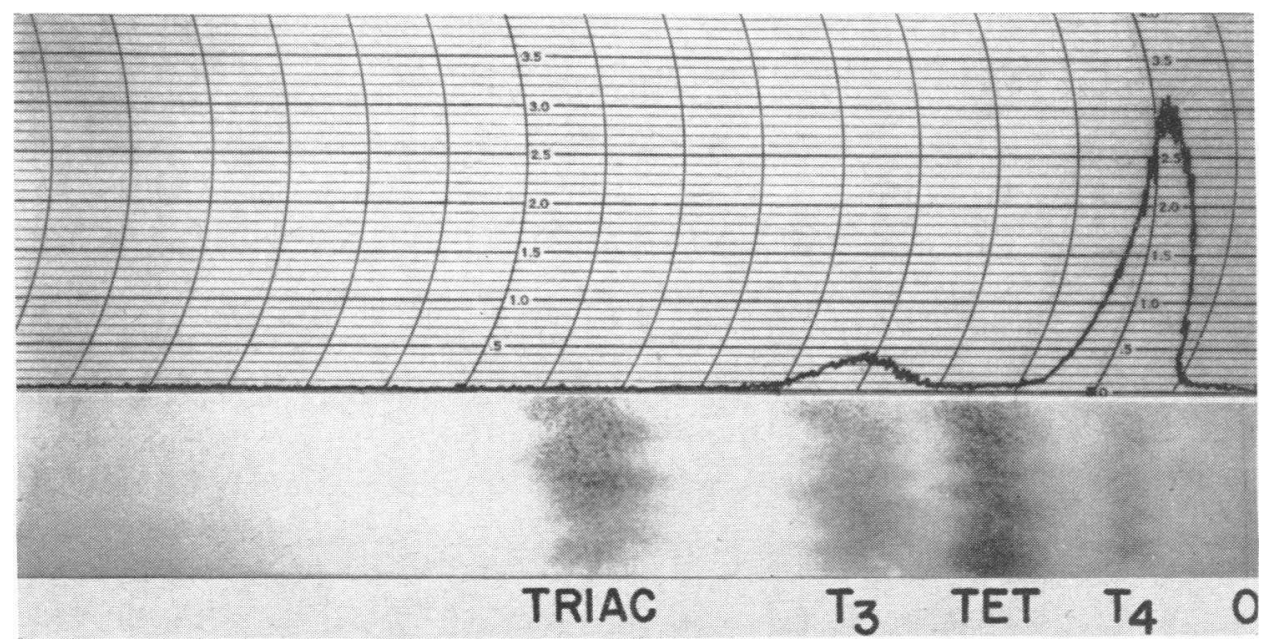

Fig. 1. Radiochromatogram FROM RAT KIDNEY SLICE EXPERIMENT SHOWING MONODEIOdiNATION OF L-THYROXINE TO TRIIODOTHYRONINE. $\mathrm{O}=$ origin of chromatogram. Position of marker compounds: $\mathrm{T}_{4}=$ thyroxine; $\mathrm{TET}=$ tetraiodothyroacetic acid; $\mathrm{T}_{3}=$ triiodothyronine $;$ TRIAC $=$ triiodothyroacetic acid. Solvent front not shown. 


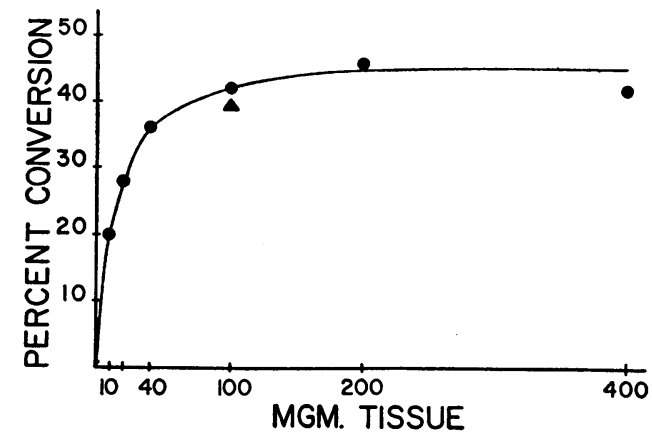

Fig. 2. Change IN Yield of tritodothyronine With VARYING AMOUNT OF ENZYME.

periment the effect of $3,3^{\prime}, 5^{\prime}$-triiodo-DL-thyronine in $10^{-6} \mathrm{M}$ concentration upon thyroxine monodeiodination is observed. The chromatogram of the tissue incubated in the absence of inhibitor shows a peak of radioactivity corresponding to the L-thyroxine substrate and a second corresponding to the reaction product $3,5,3^{\prime}$-triiodo-L-thyronine. The chromatogram of the medium from the control flask shows three peaks; the first and largest is iodide. Two peaks of radioactivity ran close to the front. These were eluted and rechromatographed in the tert-amyl alcohol- $2 \mathrm{~N} \mathrm{NH}_{4} \mathrm{OH}$ system. The first of these proved to be a mixture of thyroxine and triiodothyronine. The material which ran with the front produced several peaks on rechromatography. Only two could be identified, one of which was thyroxine and the other, present in relatively small quantities, was tetraiodothyroacetic acid.

The chromatogram of the tissue incubated in the presence of the inhibitor shows a larger thy-

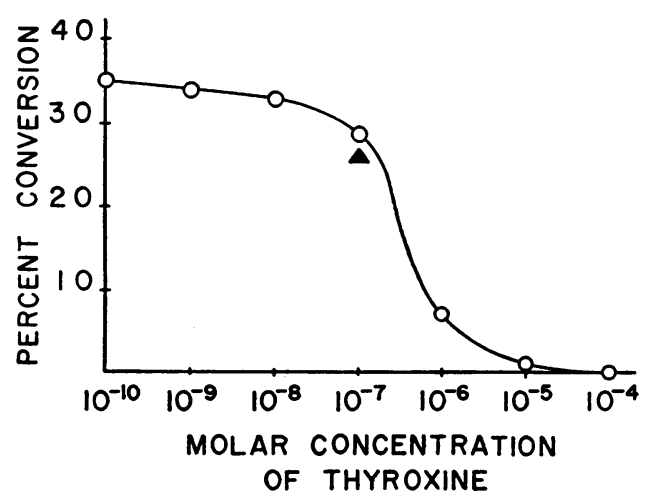

Fig. 3. Change in Yield of tritodothyronine With VARYING CONCENTRATION OF SUBSTRATE.

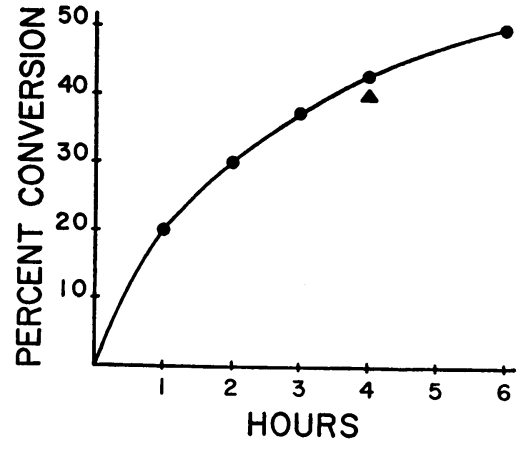

Fig. 4. Change in yield of tritodothyronine With DURATION OF INCUBATION.

roxine peak than in the control, while the triiodothyronine peak is smaller. In addition, a small peak corresponding to tetraiodothyroacetic acid appeared. The chromatograph of the medium in this instance shows a smaller iodide peak than in the control and somewhat more radioactivity at the front-running peaks. Rechromatography of the first of these two peaks revealed it to consist primarily of thyroxine. The material at the front contained again a number of unidentified compounds but a comparatively large amount of tetraiodothyroacetic acid.

Inhibition of thyroxine monodeiodination by the various analogs tested is given in Table $I$. Each value represents a mean of at least five experiments. At a concentration 10 times the molar equivalent of thyroxine present, all of the analogs induced significant inhibition with the exception of $\alpha$-methyl thyroxamine and diiodotyrosine. At the remaining concentrations varying degrees of inhibition were observed. The order of effectiveness of the analogs was consistent from one concentration to the other. Tetraiodothyropropionic acid and 3,3',5'-triiodo-DL-thyronine were most effective, followed by D-thyroxine and O-methyl-DLthyroxine. Alpha-methyl thyroxamine and diiodotyrosine were essentially inactive as inhibitors.

With high degrees of inhibition a third peak of radioactivity appeared in the chromatograms of the tissue, having an $\mathrm{Rf}$ value corresponding with tetraiodothyroacetic acid, as illustrated in Figure 6. The identity of this substance was confirmed by elution and co-crystallization to a constant specific activity with authentic tetraiodothyroacetic acid (Table II). 
CONTROL

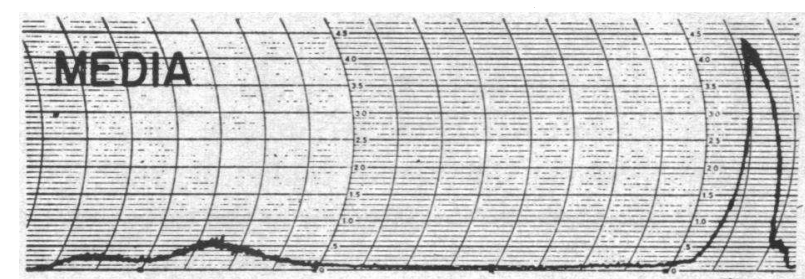

I

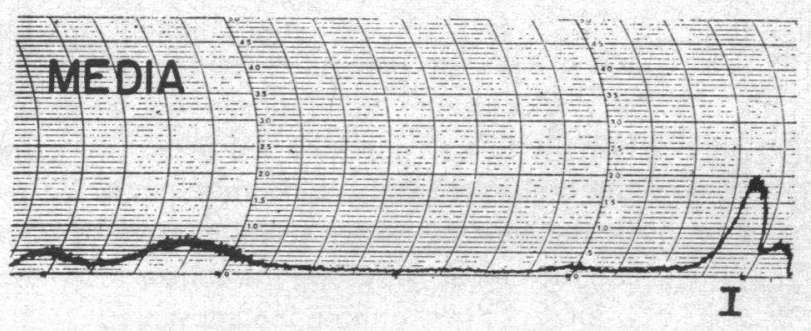

ANALOG

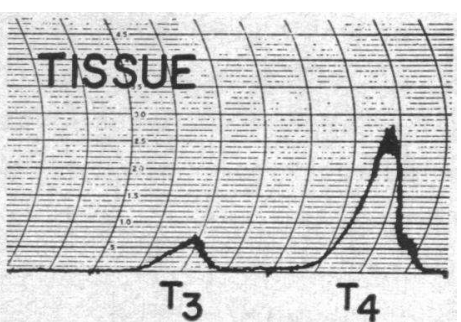

$T_{3}$

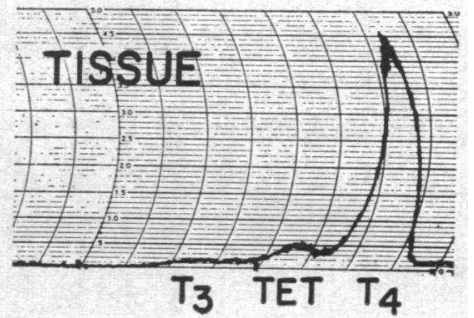

$\mathrm{T}_{3}$ TET $\mathrm{T}_{4}$

FIG. 5. RADIOCHROMATOGRAMS OF A REPRESENTATIVE INHIBITOR EXPERIMENT SHOWING EFFECT OF $3,3^{\prime}, 5^{\prime}$-TRIIODO-DL-THYRONINE IN $10^{-6} \mathrm{M}$ CONCENTRATION ON L-THYROXINE MONODEIODINATION. Position of marker compounds: $\mathrm{T}_{4}=$ thyroxine; $\mathrm{TET}=$ tetraiodothyroacetic acid; $\mathrm{T}_{3}=3,5,3^{\prime}$ triiodo-L-thyronine; $\mathrm{I}=$ iodide. Origin of chromatogram at right, front at left.

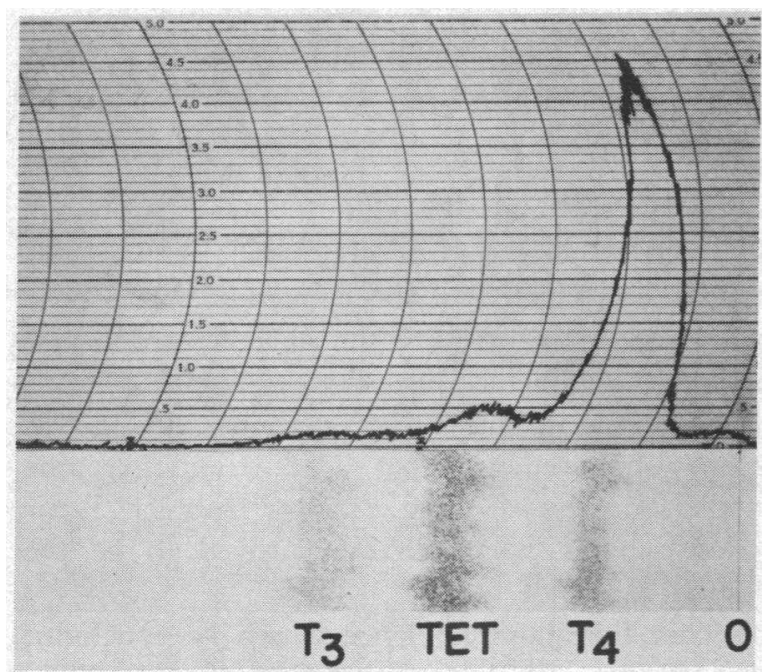

Fig. 6. Radiochromatogram of tisSUe FROM INHIBITOR EXPERIMENT SHOWING EFFECT OF 3,3',5'-TRIIODO-DLTHYRONINE IN $10^{-6} \mathrm{M}$ CONCENTRATION ON L-THYROXINE MONODEIOdination. Note reduced yield of 3,5,3'-triiodoL-thyronine and appearance of peak of radioactivity corresponding to tetraiodothyroacetic acid (compare Fig. 1). $\mathrm{O}=$ origin of chromatogram. Front not shown. Position of marker compounds: $\mathrm{T}_{4}=$ thyroxine TET $=$ tetraiodothyroacetic acid; $T_{3}=3,5,3^{\prime}$-triiodo-L-thyronine.
Structural analogs which antagonize the action of thyroxine can be expected to act through competitive inhibition; i.e., by competing with the natural substrate for the active groups on the enzyme. The activity of a competitive inhibitor, therefore, depends upon the relative concentration of the substrate and inhibitor, rather than on the inhibitor concentration alone, as in the case of a noncompetitive inhibitor. The nature of the inhibition was examined by increasing the amount of labeled substrate in the presence of a constant amount of inhibitor ( 7 ), in this case $3,3^{\prime}, 5^{\prime}$-triiodo-

TABLE II

Co-crystallization of reaction product with authentic tetraiodothyroacetic acid*

\begin{tabular}{lc}
\hline \hline & $c p m / m g$ \\
\hline Original mixture & 28,410 \\
Crystallization 1 & 16,900 \\
Crystallization 2 & 15,500 \\
Crystallization 3 & 16,050 \\
Crystallization 4 & 14,400 \\
\hline
\end{tabular}

* Kindly performed by Dr. K. Tomita, Institute for Enzyme Research, Univ. of Wisconsin. 


\section{THYROXINE INHIBITOR}

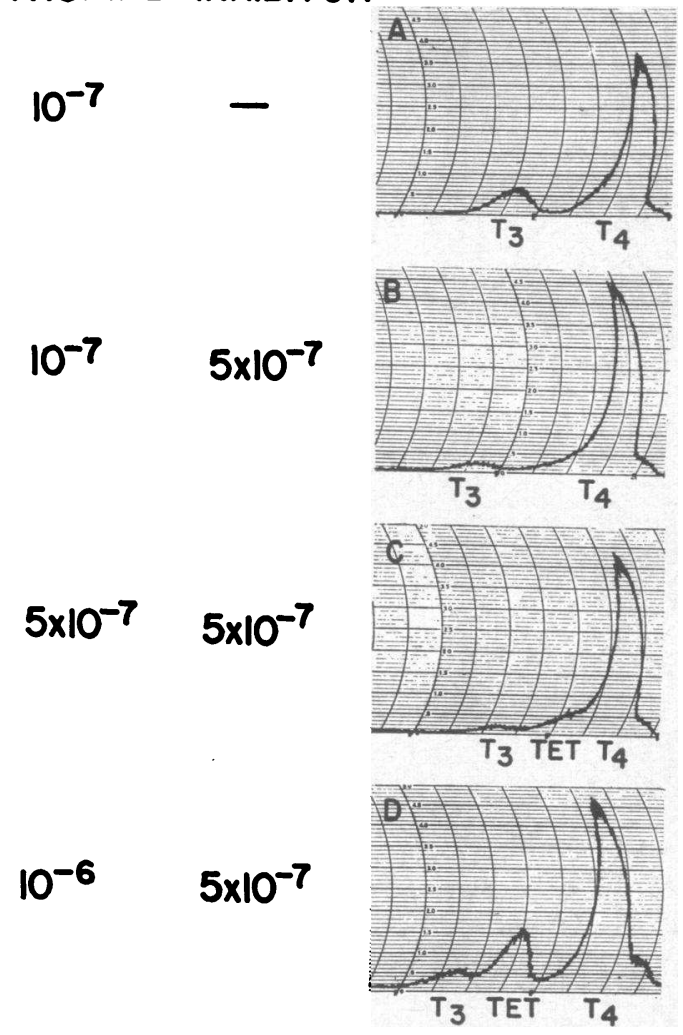

Fig. 7. Competitive inhibition of L-Thyroxine MONODEIODINATION BY 3,3',5'-TRIIODO-DL-THYRONINE. Origin of chromatogram at right, front not shown. Position of marker compounds: $T_{4}=$ thyroxine; TET $=$ tetraiodothyroacetic acid; $\mathrm{T}_{3}=3,5,3^{\prime}$-triiodo-L-thyronine. Molar concentration of thyroxine and inhibitor used are shown opposite each radioactivity record.

DL-thyronine. The results are given in Figure 7. Figure 7A illustrates the conversion of labeled $\mathrm{L}$-thyroxine to triiodothyronine in the absence of an inhibitor. In $\mathrm{B}, \mathrm{C}$, and $\mathrm{D}$ the inhibitor concentration was kept constant while the substrate concentration was increased. It will be noted that there is a reappearance of triiodothyronine with the highest concentration of the substrate, confirming the competitive nature of this inhibition. The appearance of a relatively large quantity of tetraiodothyroacetic acid when the substrate concentration reached $10^{-6} \mathrm{M}$ (Figure 7D) suggests that when the capacity of the monodeiodinating enzyme is exceeded, an alternative pathway for substrate metabolism exists via deamination and decarboxylation. Similar results have been obtained when the concentration of substrate exceeds $10^{-6}$ $M$ in the absence of an inhibitor.

\section{DISCUSSION}

The analogs selected for study permit an analysis of the structural requirements for thyroxine antagonism. The diphenyl ether configuration seems essential in an inhibitor, since diiodotyrosine did not significantly inhibit the reaction. Particular attention was given to the three reactive groups of the thyroxine molecule, since these are the most likely sites of binding between the enzyme and the substrate. That the spatial relationship of the carboxyl and amino groups is important when both are present is evident from the failure of D-thyroxine to compete on a mole-to-mole basis with L-thyroxine. Of these two groups only the carboxyl group appears to participate actively in the binding, since tetraiodothyropropionic acid is the most effective inhibitor examined and $\alpha$-methyl thyroxamine is almost without inhibitory effect. The "involvement" of the amino group may be passive-i.e., that of steric hindrance when present in the D-isomer. Methylation of the 4'-hydroxyl group reduced the inhibitory effect, indicating that this group also participates in the binding. It is likely that the binding strength contributed by this phenolic group would relate directly to the extent of its dissociation. The presence of iodine atoms ortho to this group influences this dissociation. The $\mathrm{pK}$ of the phenolic group of 3,5,3'-triiodothyronine is approximately 9.2, whereas that for thyroxine is about 6.5 (8). Thus, at a physiological $\mathrm{pH}$, this group is virtually undissociated in the compounds with only one iodine atom ortho to the phenolic group and is nearly completely dissociated in analogs with iodine atoms in both ortho positions. From this it may be predicted that $3,5,3^{\prime}$-triiodothyronine would be a less effective inhibitor than $3,3^{\prime}, 5^{\prime}$-triiodothyronine, which in fact proved to be the case (Table I).

From the above evidence it can be concluded that all three reactive groups are "involved" in the binding of thyroxine to the deiodinating enzyme. It is probable that the position of these groups is critical. A competing thyronine ana$\log$ should, therefore, present these same reactive groups in the same relative position as in thyroxine. It must also, in order to be physiologically antagonistic, possess no thyromimetic activity itself. Of all the analogs tested 3,3',5'-triiodo-L-thy- 
ronine best fits these requirements. ${ }^{1}$ This ana$\log$ is identical with thyroxine except for the absence of one of the two iodine atoms in the " $A$ " ring of the thyronine nucleus. Recent tests have indicated that it is physiologically inactive (9). The presence of two iodine atoms (or other electronegative groups) in the 3,5 positions of thyronine was suggested as requisite to physiological activity by Harington (10) and confirmed by observations of others since $(11,12)$.

It is likely that triiodothyronine is itself not the ultimate peripherally acting hormone. Further structural change may be required in the molecule before it becomes active. Changes in the alanine side chain have been proposed as one possibility. In this connection it has been demonstrated that the enzyme system which converts thyronine compounds to their corresponding thyroacetic acid analogs is not specific for the substituents on the thyronine nucleus (13). It can be expected that 3,3',5'-triiodothyronine would go through the same sequence of reactions. Thus this analog, converted to $3,3^{\prime}$-diiodothyronine by thyroxine monodeiodinase, would be successively converted to the $\alpha$-keto acid, aldehyde and acetic acid analog of this parent compound. These derivatives presumably are physiologically inactive, and by acting as competitive inhibitors at each stage, would provide a sequential block of reactions involving the alanine side chain. This hypothesis would account for the thyroxine antagonism of 3,3'-diiodothyronine and 3,3'-diiodothyropropionic acid, and the triiodothyronine antagonism of $3,3^{\prime}, 5^{\prime}$-triiodothyronine (14).

Recently Pittman and Barker (14) observed that $3,3^{\prime}, 5^{\prime}$-triiodo-DL-thyronine antagonized the metabolic-stimulating effect of thyroxine administered to thyroidectomized rats. Benua, Kumaoka, Leeper and Rawson (15) administered this compound to a hyperthyroid patient and observed a significant fall in metabolic rate. Pittman, Tingley, Nickerson and Hill (16) reported a fall in the metabolic rates of treated myxedemic patients following the administration of this analog. No

\footnotetext{
1 It should be pointed out that the $3,3^{\prime}, 5^{\prime}$-triiodothyronine tested was a racemic mixture. There is some justification for considering the effective molar ratio to be approximately one-half that recorded; thus $3,3^{\prime}, 5^{\prime}$-triiodoL-tyronine would be at least equal to tetraiodothyropropionic acid as an antagonist.
}

response was observed in one patient with hyperthyroidism, probably because of the comparatively low dosage administered. These clinical observations, together with the evidence presented here, support the concept that thyroxine is converted to more active analogs in the peripheral tissues. A rational approach to the control of hyperthyroidism through the inhibition of these reactions is possible.

The metabolism of thyroxine to tetraiodothyroacetic acid may play an important role in thyroxine antagonism. Unless an alternative pathway for the degradation of thyroxine is present it would accumulate behind the block and eventually overcome the inhibition. The fact that reactions involving the alanine side chain of thyroxine are not inhibited by $3,3^{\prime}, 5^{\prime}$-triiodothyronine is evidence that this compound is a less effective inhibitor of these reactions than of the deiodination reaction. It follows that the action of these agents as inhibitors is more likely to be at the site of monodeiodination than the subsequent alanine side chain reactions.

\section{SUMMARY}

The inhibition by thyroxine analogs of the enzymatic monodeiodination of thyroxine to $3,5,3^{\prime}$-triiodo-L-thyronine was studied in vitro with kidney slices from hyperthyroid rats as the enzyme source. Of the several analogs tested, tetraiodothyropropionic acid and 3,3',5'-triiodo-DL-thyronine proved to be the most effective inhibitors, followed by D-thyroxine and O-methyl-DL-thyroxine. Alphamethyl thyroxamine and diiodotyrosine were essentially inactive. It is suggested that all three reactive groups are involved in varying degree in effecting thyroxine antagonism, and that this inhibition is competitive in nature. These data, together with the observations by others that one of these analogs $\left(3,3^{\prime}, 5^{\prime}\right.$-triiodo-DL-thyronine $)$ blocks the metabolic effect of thyroxine in vivo, support the concept that thyroxine is converted to another compound before becoming active at the cellular level, and that one step in this conversion is the removal of one iodine atom from the terminal ring.

\section{ACKNOWLEDGMENT}

The authors wish to thank Dr. H. A. Lardy for suggestions and criticism, and Miss Sue Ames for valuable technical assistance. 


\section{REFERENCES}

1. Woolley, D. W. Structural analogues antagonistic to thyroxine. J. biol. Chem. 1946, 164, 11.

2. Selenkow, H. A., and Asper, S. P., Jr. Biological activity of compounds structurally related to thyroxine. Physiol. Rev. 1955, 35, 426.

3. Gross, J., and Pitt-Rivers, R. Physiological activity of $3: 5: 3^{\prime}$-L-triiodothyronine. Lancet 1952, 262, 593.

4. Albright, E. C., and Larson, F. C. Metabolism of L-thyroxine by human tissue slices. J. clin. Invest. 1959, 38, 1899.

5. Larson, F. C., Tomita, K., and Albright, E. C. The deiodination of thyroxine to triiodothyronine by kidney slices of rats with varying thyroid function. Endocrinology 1955, 57, 338.

6. Tomita, K., Lardy, H. A., Larson, F. C., and A1bright, E. C. Enzymatic conversion of thyroxine to tetraiodothyroacetic acid and of triiodothyronine to triiodothyroacetic acid. J. biol. Chem. 1957, 224, 387.

7. Lineweaver, H., and Burk, D. The determination of enzyme dissociation constants. J. Amer. chem. Soc. 1934, 56, 658.

8. Lardy, H. A. Effect of thyroid hormones in enzyme systems in Brookhaven Symp. in Biology No. 7, The Thyroid. Upton, N. Y., Brookhaven National Lab. 1955, p. 90.
9. Rawson, R. W., Money, W. L., Kroc, R. L., Kumaoka, S., Benua, R. S., and Leeper, R. D. A dissociation of thyroid hormonal effects by structural alteration of the thyroxine molecule. Amer. J. med. Sci. 1959, 238, 261.

10. Harington, C. R. The Thyroid Gland; Its Chemistry and Physiology. London, Oxford Univ. Press, 1933, p. 149.

11. Salter, W. T. quoted in Block, P., Jr., and Powell, G. The synthesis of $3^{\prime}, 5^{\prime}$-diiodothyronine. J. Amer. chem. Soc. 1942, 64, 1070.

12. LeBlond, C. P., and Grad, B. Thyroxine-like activity of chloro- and bromothyronine derivatives. J. Pharmacol. exp. Ther. 1948, 94, 125.

13. Tomita, K., and Lardy, H. A. Enzymic conversion of iodinated thyronines to iodinated thyroacetic acids. J. biol. Chem. 1960, 235, 3292.

14. Pittman, C. S., and Barker, S. B. Antithyroxine effects of some thyroxine analogues. Amer. J. Physiol. 1959, 197, 1271.

15. Benua, R. S., Kumaoka, S., Leeper, R. D., and Rawson, R. W. The effect of d1-3,3',5'-triiodothyronine in Graves' disease. J. clin. Endocr. 1959, 19, 1344.

16. Pittman, J. A., Tingley, J. O., Nickerson, J. F., and Hill, S. R., Jr. Antimetabolic activity of 3,3',5'-triiodo-DL-thyronine in man. Metabolism 1960, 9, 293. 